Tropical Journal of Pharmaceutical Research October 2018; 17 (10): 2037-2046

ISSN: $1596-5996$ (print); 1596-9827 (electronic)

(C) Pharmacotherapy Group, Faculty of Pharmacy, University of Benin, Benin City, 300001 Nigeria.

Available online at http://www.tjpr.org

Original Research Article

http://dx.doi.org/10.4314/tjpr.v17i10.21

\title{
Anti-MRSA potential and metabolic fingerprinting of actinobacteria from Cholistan desert, Pakistan
}

\author{
Fatima Adeela, Saba Riaz, Imran Sajid* \\ Department of Microbiology and Molecular Genetics, University of the Punjab, Lahore-54590, Pakistan \\ ${ }^{*}$ For correspondence: Email: imran.mmg@pu.edu.pk
}

Sent for review: 25 May 2018

Revised accepted: 25 September 2018

\begin{abstract}
Purpose: To investigate the actinomycetes from an extreme environment for their inhibitory potential against methicillin-resistant Staphylococcus aureus (MRSA), and the metabolic fingerprinting of the active strains.

Methods: A total of 80 actinomycetes strains were recovered from Cholistan desert, Pakistan. The isolated strains were identified by morphological, biochemical and physiological characterization and by 16S rRNA gene sequencing. The antimicrobial activity of the selected actinomycetes strains against MRSA was determined by agar well and disc diffusion assays. All the strains were screened against MRSA for the identification of potent antimicrobial producers. Further, validation of MRSA, strains was carried out using a portion of mec-A gene (533bp) of five strains including $A 1, A 6, A 7, A 8$ and $A 9$, amplified and sequenced.

Results: The desert actinomycetes strains exhibited promising antimicrobial activity against MRSA with zone of inhibition of up to $25 \mathrm{~mm}$ recorded in agar diffusion and disc diffusion assays. The MRSA strains also showed maximum genetic similarity with methicillin-resistant Staphylococcus aureus in GenBank. Most of the actinobacterial strains exhibited $99 \%$ genetic similarity with the genus Streptomyces, including strains AFD6, AFD12, AFD23, AFD25, and AFD26 while isolate AFD18 has $100 \%$ similarity with a Pseudonocardia, named Saccharothrix xinjiangensis.

Conclusion: The results reveal that actinomycetes from the desert ecosystem studied are significant producers of useful antimicrobial agents, and should be explored further for novel drug candidates against MRSA.
\end{abstract}

Keywords: Anti-MRSA potential, Actinomycetes, Extreme environments, Metabolic fingerprinting, $16 S$ rRNA gene sequencing, $M e c-A$ gene characterization

\begin{abstract}
This is an Open Access article that uses a funding model which does not charge readers or their institutions for access and distributed under the terms of the Creative Commons Attribution License (http://creativecommons.org/licenses/by/4.0) and the Budapest Open Access Initiative (http://www.budapestopenaccessinitiative.org/read), which permit unrestricted use, distribution, and reproduction in any medium, provided the original work is properly credited.

Tropical Journal of Pharmaceutical Research is indexed by Science Citation Index (SciSearch), Scopus, International Pharmaceutical Abstract, Chemical Abstracts, Embase, Index Copernicus, EBSCO, African Index Medicus, JournalSeek, Journal Citation Reports/Science Edition, Directory of Open Access Journals (DOAJ), African Journal Online, Bioline International, Open-J-Gate and Pharmacy Abstracts
\end{abstract}

\section{INTRODUCTION}

The multidrug resistant (MDR) pathogens are increasing significantly and have proved as a global economic and healthcare crisis. This phenomenon is listed to be a threat to global public health by the World Health Organization (WHO). Staphylococcus aureus is a component of the normal flora of the naso-pharynx of healthy humans. However, $S$. aureus has the capacity to strategically cause various diseases from simple skin infections to fatal necrotizing pneumonia and 
infective endocarditis, resulting in substantial global human ailment and death [1].

There are reports of resistance against methicillin that is considered the drug of choice to treat serious infections. The first resistant isolate of Staphylococcus aureus appeared two years after the introduction of penicillin in 1944. The society for healthcare epidemiology of America suggested that it is the most common etiological agent of wound infections and respiratorassociated pneumonia, causing 30 and $24 \%$ of cases, respectively [2]. The data from Pakistan suggested that $4-51 \%$ of healthcare-associated $S$. aureus cases were reportedly caused by MRSA. The use of glycopeptides (vancomycin and teicoplanin) is on the increase because of the increase in the incidence of MRSA infections. This rapid alteration in mechanism that confirms resistance is alarming [3].

Actinomycetes are biotechnologically invaluable class of prokaryotes producing bioactive secondary metabolites especially antibiotics, anticancer agents, immunosuppressive agents and enzymes [4]. These are the prime sources of clinically important antibiotics making three quarters of all known antibiotics, most of which are too complex to be synthesized by conjugative chemistry. Among actinomycetes, the Streptomyces are more competitive, producing approximately $80 \%$ of total antibiotic products. Micromonospora constitute the second best with less than one-tenth as many as Streptomyces. To avoid the redundancy in the discovery of antimicrobial compounds from normal habitats, scientists have been searching unexplored ecosystems like deserts, lakes, marines etc., for the discovery of novel bioactive compounds [5].

Desert is a rare ecological niche with respect to antimicrobial research. The present study specifically aims at the exploration of a unique and harsh ecosystem of desert in Pakistan, for the isolation and screening of actinomycetes for antimicrobial compounds against MRSA. Sand and soil samples were collected from Cholistan desert located in south-west of the Punjab province of Pakistan [6]. On the basis of parent material, topography and soil flora this desert is divided into two geomorphic regions Lesser Cholistan or northern region and Greater Cholistan or southern region. The climate of this desert is sub-tropical, rough, hot and tedious, and influenced by seasonal monsoons. A very notable feature of the Cholistan desert is the scarcity of rainfall for up to 4-6 years continually. In summer season the mean temperature varies from 35 to $50^{\circ} \mathrm{C}$ during May to June and in winter from 15 to $20 \stackrel{\circ}{\mathrm{C}}$ during December to February [7].

\section{EXPERIMENTAL}

\section{Sample collection}

Fifteen soil and sand samples were collected from various sites of Cholistan desert in district Rahim Yar Khan, Pakistan, in clean polythene bags. The samples were processed by physical and chemical treatments (Heat treatment at 50 $55^{\circ} \mathrm{C}$ for $3-7$ days) following the methods described by Hayakawa and Nonomura [8] for the enrichment of actinomycetes.

\section{Isolation of actinomycetes}

One gram of each soil sample was suspended in $10 \mathrm{~mL}$ of sterile water and vortexing was done for $45 \mathrm{sec}$. Glycerol-casein- $\mathrm{KNO}_{3}$ agar (glycerol 10 $\mathrm{g}, \mathrm{KNO}_{3} 2 \mathrm{~g}$, casein $0.3 \mathrm{~g}, \mathrm{NaCl} 2 \mathrm{~g}, \mathrm{~K}_{2} \mathrm{HPO}_{4} 2 \mathrm{~g}$, $\mathrm{MgSO}_{4} .7 \mathrm{H}_{2} \mathrm{O} 0.05 \mathrm{~g}, \mathrm{CaCO}_{3} 0.02 \mathrm{~g}, \mathrm{FeSO}_{4} .7 \mathrm{H}_{2} \mathrm{O}$ $0.01 \mathrm{~g}$, agar $18 \mathrm{~g}$ in one liter) was prepared and sterilized at $121^{\circ} \mathrm{C}$ in $15 \mathrm{lbs}$ pressure for $15 \mathrm{~min}$. The media was supplemented with $50 \mu \mathrm{g} / \mathrm{mL}$ of nystatin to prevent the growth of fungal contaminants. The sand and soil samples were serially diluted and $0.1 \mathrm{~mL}$ of the dilution $10^{-3}$ was spread on the surface of the glycerol-casein$\mathrm{KNO}_{3}$ agar. The plates were then incubated at $28^{\circ} \mathrm{C}$ for 7 - 15 days. The presumptive actinomycetes colonies were selected and were transferred to the cultivation medium for actinomycetes, i.e., GYM agar (10 g malt extract, $5 \mathrm{~g}$ yeast extract, $5 \mathrm{~g}$ glucose, $15 \mathrm{~g}$ agar in one liter of distilled water) [9]. The selected colonies were purified by continuous sub culturing on GYM agar.

\section{Identification of the actinomycetes}

The selected actinomycetes strains were identified through morphological, biochemical and physiological characterization and by $16 \mathrm{~S}$ rRNA gene sequencing. The morphological characteristics including colony morphology, aerial and substrate mycelia and pigmentation were studied after cultivating the individual strains on GYM agar by the methods described by Bensultana et al. [10]. The selected strains were investigated for biochemical characteristics including melanin production, sugar utilization as carbon source, formation of organic acids, organic acid and oxalate utilization, hydrolysis of esculin and urease. For 16S rRNA gene sequencing, genomic DNA of selected desert actinomycete strains was isolated from mycelia, by using tissue genomic DNA kit (FavorPrep ${ }^{\mathrm{TM}}$, Cat\# FATGK001-1). PCR amplification of $16 \mathrm{~S}$ rRNA gene was done by using primers (27f: 
AGAGTTTGATCCTGGCTCAG) and (1522r: AAGGAGGTGATCCARCCGCA). The PCR products were purified by gel purification kit (FavorPrep $^{\mathrm{TM}}$, Cat\# FAGPK001-1) and the purified product was sequenced. In order to determine the genetic similarity of the strains with already reported data in gene bank, the sequenced data was analyzed through the BLAST search program at the NCBI website: http://www.ncbi.nlm.nih.gov/BLAST.

\section{Collection and identification of MRSA}

The clinical strains of methicillin resistant $S$. aureus (MRSA) were collected from Citi Lab, Lahore, Pakistan. Molecular characterization of MRSA was performed by mecA gene amplification [11] and by disc diffusion antibiotics sensitivity assay using methicillin (10 $\mu \mathrm{g})$, oxacillin $(1 \mu \mathrm{g})$ and cefoxitin $(30 \mu \mathrm{g})$ discs according to CLSI standards 2017 [12].

\section{Small scale cultivation of desert actinomycetes and preparation of crude extracts}

The selected desert actinomycetes were cultivated on small scale as shaking cultures in GYM broth (500 $\mathrm{mL}$ to $1 \mathrm{~L}$ culture broth) and the crude extracts were obtained which were screened biologically and chemically. The crude extracts were obtained by solvent-solvent extraction using ethyl acetate.

\section{Determination of antimicrobial activity of desert actinomycetes against MRSA}

Antimicrobial activity of the strains was determined by agar plug and well diffusion methods against MRSA strains by using the method described by Sajid et al. [13]. The results of the assays were recorded after overnight incubation by measuring the zones of inhibition around the wells in $\mathrm{mm}$.

\section{Metabolic fingerprinting of the methanol extracts}

The extracts were screened chemically by TLC using two staining reagents and HPLC-UV as described below.

\section{Thin-layer chromatography (TLC)}

The crude extracts were analyzed on TLC plate (TLC Silica gel $60 \mathrm{~F}_{254}$, Merck, Germany) to determine the presence of various compounds adopting the procedure described by Sajid et al [13]. Each of the samples was spotted repeatedly on the TLC plate by means of a capillary which was then developed with $5 \%$ $\mathrm{MeOH} / \mathrm{CH}_{2} \mathrm{Cl}_{2}$ solvent system and visualized under U.V. (254 and $366 \mathrm{~nm}$ ) by a UV lamp (CAMAG). One of the plates was sprayed with anisaldehyde/sulfuric acid (methanol, acetic acid, $\mathrm{H}_{2} \mathrm{SO}_{4}$, anisaldehyde) and the other with Ehrlich's reagent (methanol, $\mathrm{HCl} 37 \%$, 4-dimethylamino benzaldehyde) for the detection of different compounds. The colored bands that appeared were marked and recorded [13].

\section{High performance liquid chromatography (HPLC-UV) analysis}

HPLC-UV analysis was performed on clarity chromatography data system (single channel serial port) Sykum S1122 delivery system. For the chromatographic separation, the column used was RPC18 from ThermoHypersil-Keystone (dimensions $250 \times 4.6 \mathrm{~mm}$ and $5 \mu \mathrm{m}$ particle size). Methanol and water (9:1) was used as mobile phase and flow rate was adjusted to 1 $\mathrm{mL} / \mathrm{min}$. The crude extract was dissolved in HPLC grade methanol and $20 \mu \mathrm{L}$ of sample was injected into the system with the help of a microsyringe. All of the samples were run for $20 \mathrm{~min}$ and UV absorbance of the crude extract of actinomycetes strains was determined at $254 \mathrm{~nm}$. The peaks observed at different retention times $\left(t_{\mathrm{R}}\right)$ were later compared with the UV absorbance data of secondary metabolites in order to get an idea about the nature of compounds produced by the selected desert actinomycetes.

\section{Bioautography}

The crude extracts of desert actinomycetes obtained by solvent extraction were spotted on TLC plates (TLC Silica gel $60 F_{254}$, Merck, Germany), which were developed with $5 \%$ $\mathrm{CH}_{2} \mathrm{Cl}_{2} / \mathrm{MeOH}$ solvent system. For each of the sample, TLC plate was cut into two halves, one was used as a reference and sprayed with staining reagent (anisaldehyde/ $\mathrm{H}_{2} \mathrm{SO}_{4}$ ) and the other half was placed inverted on the LB agar seeded with MRSA strain. This plate was then incubated for $24 \mathrm{~h}$ at $37^{\circ} \mathrm{C}$. The zone of inhibition was measured after incubation and the active components were compared with the reference plate, marked and were scanned [13].

\section{RESULTS}

Taxonomic characteristics of the desert actinomycetes

A total of 30 desert actinomycetes strains were isolated, all of the strains showed hard, deeprooted and rough colonies with regular or irregular margins and different colony sizes 
ranges from pinpoint to large (e.g., $3 \mathrm{~mm}$ ). The color of the spores produced by these strains and their consistency was different. The strain AFD2, AFD3, AFD5, AFD6, AFD7, and AFD8 had greenish colored spores. The strains AFD1, AFD4, AFD9, AFD11, AFD23 and AFD29 produced yellow colored spores, while AFD10, AFD12 and AFD13 produced pink colored spores. The strains AFD15 and AFD20 produced orange colored spores, while all other strains produced white colored spores.

In biochemical and physiological characterization, the strains displayed the production of melanin pigment and exhibited their growth on different sugars as carbon source. Sixteen out of thirty strains tested were able to produce melanin including the strains AFD1, AFD2, AFD3, AFD6, AFD6, AFD7, AFD9, AFD12, AFD13, AFD15, AFD18, AFD20, AFD21, AFD21, AFD22, AFD23 and AFD29. All of the strains utilized glucose and mannose as carbon sources except only one strain AFD23 which could not grow on mannose. Fructose was utilized, except four strains namely AFD6, AFD14, AFD20 and AFD26. L-arabinose was used as a carbon source by nineteen of the strains, galactose and mannose by seventeen strains as carbon. The least utilized sugar was inositol as half of the strains were able to grow on it and the sucrose, only eight strains were able to use it namely AFD1, AFD2, AFD4, AFD9, AFD10, AFD19, AFD22 and AFD24 (Table 1). The comparison of taxonomic characteristics of these desert actinomycete strains with already reported data in Bergey's Manual of Systematic Bacteriology [14] provided a hint about their genus.

The genetic characterization of the strains was carried out by isolating the genomic DNA of eleven most anti-MRSA strains including AFD1, AFD2, AFD5, AFD6, AFD12, AFD15, AFD18, AFD20, AFD23, AFD25 and AFD26. The BLAST analysis of $16 \mathrm{~S}$ rRNA gene sequences of the selected desert actinomycetes strains showed similarity with already reported 16S rRNA sequences in GenBank. The strain AFD6 showed $99 \%$ similarity with Streptomyces thermolilacinus strain NBRC 14274, AFD12 and AFD25 showed $99 \%$ similarity with Streptomyces werraensis strain NBRC 13404, AFD18 showed $100 \%$ similarity with Saccharothrix xinjiangensis strain AS 4.1731, AFD23 and AFD26 showed $99 \%$ similarity with Streptomyces albaduncus strain NBRC 13397, (Table 2).

Table 1: Melanin production and utilization of different sugars as carbon source by desert actinomycetes strains

\begin{tabular}{|c|c|c|c|c|c|c|c|c|c|}
\hline Strains & $\begin{array}{l}\text { Melanin } \\
\text { production }\end{array}$ & $\begin{array}{l}\text { D- } \\
\text { glucose }\end{array}$ & $\begin{array}{l}\text { D- } \\
\text { fructose }\end{array}$ & $\begin{array}{l}\text { L- } \\
\text { arabinose }\end{array}$ & $\begin{array}{l}\text { D- } \\
\text { mannitol }\end{array}$ & Sucrose & Inositol & $\begin{array}{l}\text { D- } \\
\text { galactose }\end{array}$ & Mannose \\
\hline AFD1 & + & + & + & + & + & + & + & + & + \\
\hline AFD2 & + & + & + & + & + & + & + & + & + \\
\hline AFD3 & + & + & + & + & - & - & + & + & + \\
\hline AFD4 & - & + & + & - & - & + & - & - & + \\
\hline AFD5 & - & + & + & + & + & - & + & - & + \\
\hline AFD6 & + & + & - & + & + & - & - & + & + \\
\hline AFD7 & + & + & + & - & + & - & - & - & + \\
\hline AFD8 & - & + & + & + & - & - & + & - & + \\
\hline AFD9 & + & + & + & + & + & + & + & + & + \\
\hline AFD10 & - & + & + & + & + & + & + & + & + \\
\hline AFD11 & - & + & + & - & + & - & + & + & + \\
\hline AFD12 & + & + & + & - & + & - & + & - & + \\
\hline AFD13 & + & + & + & + & - & - & - & - & + \\
\hline AFD14 & - & + & - & + & - & - & - & - & + \\
\hline AFD15 & + & + & + & + & - & - & - & + & + \\
\hline AFD16 & - & + & + & - & - & - & - & - & + \\
\hline AFD17 & - & + & + & - & - & - & - & - & + \\
\hline AFD18 & + & + & + & + & - & - & - & + & + \\
\hline AFD19 & - & + & + & + & - & + & - & - & + \\
\hline AFD20 & + & + & - & + & - & - & - & - & + \\
\hline AFD21 & + & + & + & - & + & - & + & + & + \\
\hline AFD22 & + & + & + & + & + & + & + & + & + \\
\hline AFD23 & + & + & + & - & + & - & + & - & - \\
\hline AFD24 & - & + & + & + & + & + & + & + & + \\
\hline AFD25 & - & + & + & + & + & - & + & + & + \\
\hline AFD26 & - & + & - & + & + & - & + & + & + \\
\hline AFD27 & + & + & + & - & + & - & - & + & + \\
\hline AFD28 & - & + & + & - & + & - & - & + & + \\
\hline AFD29 & + & + & + & - & - & - & - & - & + \\
\hline AFD30 & - & + & + & + & - & - & - & + & + \\
\hline
\end{tabular}

Key: $(+)=$ melanin production and growth on sugar, $(-)=$ no melanin is produced and no growth on sugar 
Table 2: GenBank accession numbers of the selected desert actinomycetes and MRSA strains along with their percentage similarities with different strains reported in GenBank

\begin{tabular}{|c|c|c|c|c|}
\hline $\begin{array}{l}\text { Desert } \\
\text { actinomycete } \\
\text { strains }\end{array}$ & $\begin{array}{c}\text { No. of } \\
\text { nucleotides } \\
\text { sequenced } \\
\text { (bp) }\end{array}$ & $\%$ Similarity with & & $\begin{array}{c}\text { Gene bank } \\
\text { accession } \\
\text { numbers }\end{array}$ \\
\hline AFD6 & 1270 & $\begin{array}{l}\text { Streptomyces thermolilacinus } \\
\text { strain NBRC } 14274\end{array}$ & $99 \%$ & KX131166 \\
\hline AFD12 & 950 & $\begin{array}{l}\text { Streptomyces werraensis } \\
\text { strain NBRC } 13404\end{array}$ & $99 \%$ & KX131167 \\
\hline AFD18 & 1030 & $\begin{array}{l}\text { Saccharothrix xinjiangensis } \\
\text { strain AS } 4.1731\end{array}$ & $100 \%$ & KX094938 \\
\hline AFD23 & 1430 & $\begin{array}{l}\text { Streptomyces albaduncus } \\
\text { strain NBRC } 13397\end{array}$ & $99 \%$ & $\mathrm{KX} 131165$ \\
\hline AFD25 & 1000 & $\begin{array}{l}\text { Streptomyces werraensis } \\
\text { NBRC } 13404\end{array}$ & $99 \%$ & $\mathrm{KX} 131168$ \\
\hline AFD26 & 1250 & $\begin{array}{l}\text { Streptomyces albaduncus } \\
\text { strain NBRC } 13397\end{array}$ & $99 \%$ & KX131169 \\
\hline \multicolumn{5}{|l|}{ MRSA strains } \\
\hline $\mathrm{A} 1$ & 1219 & $\begin{array}{l}\text { Staphylococcus aureus strain } \\
\text { ATCC } 12600\end{array}$ & $100 \%$ & KU662352 \\
\hline $\mathrm{A} 2$ & 1190 & $\begin{array}{l}\text { Staphylococcus aureus strain } \\
\text { NBRC } 100910\end{array}$ & $100 \%$ & KU662353 \\
\hline A5 & 1000 & $\begin{array}{l}\text { Staphylococcus aureus subsp. } \\
\text { aureus N315 strain }\end{array}$ & $100 \%$ & KR862284 \\
\hline A6 & 1250 & $\begin{array}{l}\text { Staphylococcus aureus subsp. } \\
\text { aureus N315 strain }\end{array}$ & $100 \%$ & KR862285 \\
\hline A7 & 1530 & $\begin{array}{l}\text { Staphylococcus aureus strain } \\
\text { S33 R }\end{array}$ & $99 \%$ & KR862291 \\
\hline A8 & 1050 & $\begin{array}{l}\text { Staphylococcus aureus subsp. } \\
\text { anaerobius strain MVF-7 }\end{array}$ & $100 \%$ & KU662354 \\
\hline A9 & 1070 & $\begin{array}{l}\text { Staphylococcus aureus strain } \\
\text { NBRC } 100910\end{array}$ & $99 \%$ & KR862287 \\
\hline A11 & 1290 & $\begin{array}{l}\text { Staphylococcus aureus strain } \\
\text { ATCC } 12600\end{array}$ & $100 \%$ & KR862288 \\
\hline A12 & 1410 & $\begin{array}{l}\text { Staphylococcus aureus subsp. } \\
\text { aureus } \mathrm{JH} 1\end{array}$ & $97 \%$ & KR862289 \\
\hline A14 & 1120 & $\begin{array}{l}\text { Staphylococcus aureus subsp. } \\
\text { anaerobius strain MVF-7 }\end{array}$ & $100 \%$ & KU662355 \\
\hline
\end{tabular}

\section{Taxonomic characteristics of MRSA}

All of the MRSA strains showed yellowish, round, smooth, small colonies (pinpoint to $2 \mathrm{~mm}$ ) with regular margins. Under the compound microscope (OLYMPUS CX21), all of these appeared as clusters of cocci which were gram positive. In biochemical characterization, all the strains showed the production of catalase enzyme by converting hydrogen peroxide to water and oxygen. All of these were capable to produce DNase enzyme. These were confirmed as MRSA based on their resistance to antibiotics methicillin $(10 \mu \mathrm{g})$, oxacillin $(1 \mu \mathrm{g})$ and cefoxitin $(30 \mu \mathrm{g})$. According to the CLSI standards of 2017 [12] all of the strains exhibited less than $19 \mathrm{~mm}$ zone of inhibition against cefoxitin disc which was used as their confirmation test.

The genomic DNA of all the MRSA strains was extracted, amplified and characterized by using PCR amplification. The 16S rRNA gene sequence data of all the MRSA strains was analyzed by BLAST analysis which showed similarity with already reported 165 rRNA sequences in GenBank. The strain A1 showed $100 \%$ similarity with Staphylococcus aureus strain ATCC 12600, A2 showed $100 \%$ similarity with Staphylococcus aureus strain NBRC 100910, strain A5 showed $100 \%$ similarity with Staphylococcus aureus subsp. aureus N315 strain, A6 showed $99 \%$ with Staphylococcus aureus subsp. aureus N315 strain, A7 showed $99 \%$ similarity with Staphylococcus aureus strain S33 R. The strain A8 showed $100 \%$ similarity with Staphylococcus aureus subsp. anaerobius strain MVF-7, strain A9 showed $99 \%$ similarity with Staphylococcus aureus strain NBRC 100910, the strain A11 showed $100 \%$ similarity with Staphylococcus aureus strain ATCC 12600, A12 showed $97 \%$ similarity with Staphylococcus aureus subsp. aureus $\mathrm{JH} 1$, strain $\mathrm{A} 14$ showed $100 \%$ similarity with Staphylococcus aureus subsp. anaerobius strain MVF-7 (Table 2). 
For further confirmation of the strains as MRSA, a portion of mec-A gene (533bp) of five strains including A1, A6, A7, A8 and A9 was amplified and sequenced. The BLAST analysis of this gene sequence data showed alignments with already reported mec- $A$ gene sequences in GenBank. The mec- $A$ gene sequence of MRSA isolate A1 showed $100 \%$ similarity with Staphylococcus aureus JCSC6945 mec-A gene for PBP2a family beta-lactam-resistant peptidoglycan transpeptidase mec- $A$. The mec- $A$ gene sequence of isolate A6 showed $100 \%$ similarity with Staphylococcus aureus TN/CN/1/12 mec- $A$ gene for PBP2a family betalactam-resistant peptidoglycan transpeptidase mec- $A$. The mec- $A$ gene sequence of MRSA isolate A7 showed $100 \%$ similarity with Staphylococcus aureus JCSC6943 mec-A gene for PBP2a family beta-lactam-resistant peptidoglycan transpeptidase mec- $A$. The mec- $A$ gene sequence of isolate A8 showed $100 \%$ similarity with Staphylococcus aureus $\mathrm{TN} / \mathrm{CN} / 1 / 12$ mec- $A$ gene for PBP2a family betalactam-resistant peptidoglycan transpeptidase mec- $A$. The mec- $A$ gene sequence of MRSA isolate A9 showed $100 \%$ similarity with Staphylococcus aureus subsp. aureus N315 mec- $A$ gene for PBP2a family beta-lactamresistant peptidoglycan transpeptidase mec- $A$ (Table 3).

\section{Antimicrobial activity of desert actinomycetes against MRSA}

The selected desert actinomycete strains exhibited very promising antimicrobial activity against MRSA. In case of the actinomycete strain AFD2, maximum zone of inhibition recorded was $36 \mathrm{~mm}$ against MRSA isolate A11 and $16 \mathrm{~mm}$ zone against MRSA isolate $A 5,24 \mathrm{~mm}$ against MRSA strains $A 6$ and $A 7 ; 28 \mathrm{~mm}$ zone of inhibition against MRSA isolate $A 9$ and $25 \mathrm{~mm}$ zone of inhibition against MRSA isolate A12. The other highly active actinomycete strain was AFD9, which exhibited maximum zone of inhibition against MRSA isolate A12 up to 30 $\mathrm{mm}, 26 \mathrm{~mm}$ zone of inhibition against MRSA isolate $A 5,24 \mathrm{~mm}$ zone against MRSA strains A6, A7 and A11 while $23 \mathrm{~mm}$ zone of inhibition against MRSA isolate A9. Among other desert actinomycete, the strain AFD10 also showed very good antibacterial activity as it expressed 28 $\mathrm{mm}$ zone of inhibition against MRSA strains A5 and $A 12$, and $22 \mathrm{~mm}$ zone of inhibition against MRSA isolate A9. The strain AFD22 was another very active strain and it exhibited $24 \mathrm{~mm}$ zone of inhibition against MRSA isolate A12, $22 \mathrm{~mm}$ zone of inhibition against MRSA isolate A11 while $20 \mathrm{~mm}$ zone of inhibition against MRSA strains A6, A7 and A9 and $19 \mathrm{~mm}$ zone of inhibition against MRSA isolate A5. The desert actinomycete strain AFD24 also exhibited good antimicrobial activity against different MRSA strains, it showed $22 \mathrm{~mm}$ zone of inhibition against MRSA isolate A12, $21 \mathrm{~mm}$ zone of inhibition against MRSA isolate $A 7,20 \mathrm{~mm}$ zone of inhibition against MRSA strains $A 6$ and $A 11$, $18 \mathrm{~mm}$ zone of inhibition against MRSA isolate A5 and $17 \mathrm{~mm}$ zone of inhibition against MRSA isolate A9 (Figure $1 \mathrm{~A}, \mathrm{~B}$ and D, Table 4).

\section{Chemical profile of methanol extracts of desert actinomycetes}

In chemical profiling, the crude extracts of desert actinomycetes were analyzed by TLC and HPLCUV. In case of TLC the UV visible spots were analyzed under UV at short and long wavelength (254 and $366 \mathrm{~nm}$ ).

Table 3: Similarity of $m e c-A$ gene of MRSA strains with genes already repoted in GenBank

\begin{tabular}{lclc}
\hline $\begin{array}{l}\text { MRSA } \\
\text { strains }\end{array}$ & $\begin{array}{c}\text { No. of } \\
\text { nucleotides } \\
\text { sequenced }\end{array}$ & Similarity with & $\begin{array}{c}\text { Score } \\
(\%)\end{array}$ \\
\hline A1 & 510 & $\begin{array}{l}\text { Staphylococcus aureus JCSC6945 mecA gene for } \\
\text { PBP2a family beta-lactam-resistant peptidoglycan } \\
\text { transpeptidase MecA }\end{array}$ & 100 \\
A6 & 510 & $\begin{array}{l}\text { Staphylococcus aureus TN/CN/1/12 mecA gene for } \\
\text { PBP2a family beta-lactam-resistant peptidoglycan } \\
\text { transpeptidase MecA } \\
\text { Staphylococcus aureus JCSC6943 mecA gene for }\end{array}$ & 100 \\
A7 & 510 & $\begin{array}{l}\text { PBP2a family beta-lactam-resistant peptidoglycan } \\
\text { transpeptidase MecA } \\
\text { Staphylococcus aureus TN/CN/1/12 mecA gene for }\end{array}$ & 100 \\
A8 & 500 & $\begin{array}{l}\text { PBP2a family beta-lactam-resistant peptidoglycan } \\
\text { transpeptidase MecA } \\
\text { Staphylococcus aureus subsp. aureus N315 mecA } \\
\text { gene for PBP2a family beta-lactam-resistant } \\
\text { peptidoglycan transpeptidase MecA }\end{array}$ & 100 \\
& 500 & & \\
\hline
\end{tabular}


Table 4: Antimicrobial activity of the selected desert actinomycetes against various MRSA (methicillin resistant Staphylococcus aureus) strains

\begin{tabular}{|c|c|c|c|c|c|c|}
\hline \multirow[t]{2}{*}{ Actinomycete Strains } & \multicolumn{6}{|c|}{ Zone of inhibition (mm) against various MRSA strains } \\
\hline & A5 & A6 & A7 & A9 & A11 & A12 \\
\hline AFD1 & 18 & 11 & 11 & 10 & 14 & 18 \\
\hline AFD2 & 16 & 24 & 24 & 28 & 36 & 25 \\
\hline AFD3 & 18 & 12 & 13 & 12 & 15 & 12 \\
\hline AFD4 & 16 & 13 & 12 & 10 & 10 & 14 \\
\hline AFD5 & 16 & 12 & 14 & - & 18 & 12 \\
\hline AFD6 & 8 & - & - & 10 & - & - \\
\hline AFD7 & - & - & - & 8 & - & 8 \\
\hline AFD8 & 10 & - & - & 10 & 10 & - \\
\hline AFD9 & 26 & 24 & 24 & 23 & 24 & 30 \\
\hline AFD10 & 28 & 22 & 21 & 22 & 20 & 28 \\
\hline AFD11 & 14 & 12 & - & 11 & - & 12 \\
\hline AFD12 & 16 & 12 & 12 & 14 & 14 & 12 \\
\hline AFD13 & 14 & 11 & 11 & 9 & 11 & 12 \\
\hline AFD14 & - & 17 & 23 & 18 & 11 & - \\
\hline AFD15 & 11 & 10 & - & - & - & - \\
\hline AFD16 & 14 & 14 & 12 & 11 & 11 & 10 \\
\hline AFD17 & 11 & 10 & - & 10 & - & 10 \\
\hline AFD18 & 12 & - & - & - & - & - \\
\hline AFD19 & - & - & - & - & - & 10 \\
\hline AFD20 & 15 & 16 & 14 & 18 & 14 & 18 \\
\hline AFD21 & 12 & 17 & 16 & 16 & 10 & 14 \\
\hline AFD22 & 19 & 20 & 20 & 20 & 22 & 24 \\
\hline AFD23 & - & 16 & 18 & 20 & 16 & 16 \\
\hline AFD24 & 18 & 20 & 21 & 17 & 20 & 22 \\
\hline AFD25 & 12 & 16 & 16 & 12 & 14 & 10 \\
\hline AFD26 & 12 & 16 & 16 & 14 & 12 & 12 \\
\hline AFD27 & 11 & 16 & 18 & 17 & 10 & 16 \\
\hline AFD28 & 11 & 13 & 11 & 14 & 10 & 11 \\
\hline AFD29 & 10 & 10 & 10 & 11 & 10 & 10 \\
\hline AFD30 & 14 & 24 & 13 & - & 12 & 10 \\
\hline
\end{tabular}

Zone of inhibition in millimeters $(\mathrm{mm})$
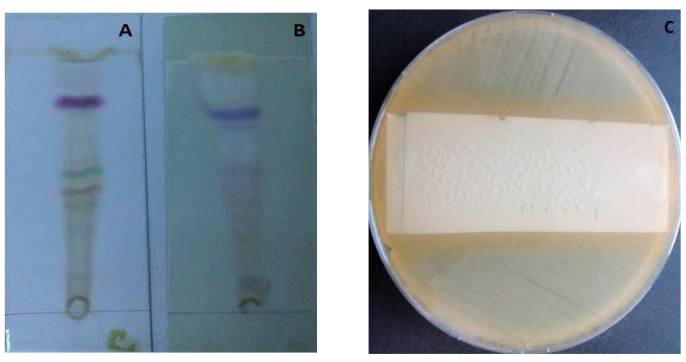

Plate 1: (A) Metabolic fingerprints of actinomycete strain AFD2 on TLC after treatment with anisaldehyde $/ \mathrm{H}_{2} \mathrm{SO}_{4}$ and (B) Ehrlich's reagent; (C) Bioautography of actinomycete strain AFD9

Most of the components of the crude extracts of these strains had the absorptive capacity for UV and some noticeable bands were observed in the extracts of strains AFD2, AFD9, AFD10, AFD22 and AFD24 (Figure $2 \mathrm{~A}$ and B). The pattern of colored bands on TLC plates after treatment with different staining reagents (anisaldehyde/ $\mathrm{H}_{2} \mathrm{SO}_{4}$ and Ehrlich's reagent) is visible in Figure 1 ( $\mathrm{E}$ and $\mathrm{F}$ ). The components of the crude extracts of strains AFD9, AFD10, AFD20, AFD22 and AFD24 produced different colors when treated with anisaldehyde/ $\mathrm{H}_{2} \mathrm{SO}_{4}$ blue, green or violet spots appeared in 10 min (Figure 1 E) representing the presence of sugar molecules [15]. The treatment with Ehrlich's reagent resulted in blue colored bands representing the presence of indole or indole like compounds in the crude extract of AFD2 (Figure 1 F).

In HPLC-UV analysis of the crude extracts of the selected desert actinomycetes each of the strains displayed variety of peaks at different retention times $\left(t_{\mathrm{R}}\right)$. For instance, crude extract of the strain AFD23 exhibited 8 peaks and the major peak was at $t_{\mathrm{R}} 2.37 \mathrm{~min}$, with the peak area of 5104.438 mV.s. (Figure 3).While the crude extracts of AFD6, AFD9, AFD18 and AFD27 showed number of peaks at different retention times $\left(t_{R}\right)$ with different peak areas.

The bioautographic assay (Figure 1C) performed with crude extracts of actinomycete strains AFD13, AFD9 and AFD23 revealed that different fractions in the extracts exhibited antimicrobial activity against MRSA strains. The strain AFD9 produced 5 fractions, two of them exhibited pronounced antimicrobial activity against MRSA 
strain A5 and one fraction exhibited antimicrobial activity against MRSA strain A6 (Figure 2 C, D).

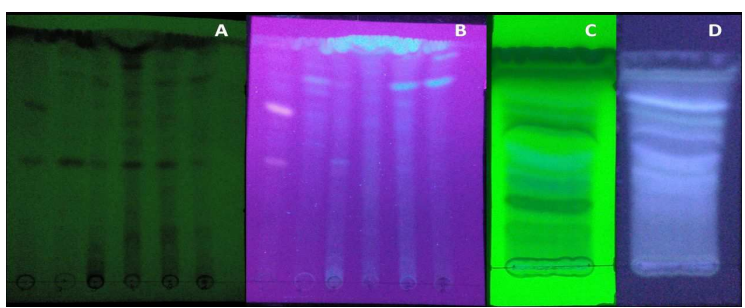

Plate 2: Metabolic fingerprints of various desert actinomycete strains on TLC under UV (A) $254 \mathrm{~nm}$ (B) $366 \mathrm{~nm}$ (C) bioautography of strain AFD9 under UV $254 \mathrm{~nm}$ (D) under $366 \mathrm{~nm}$ wavelength

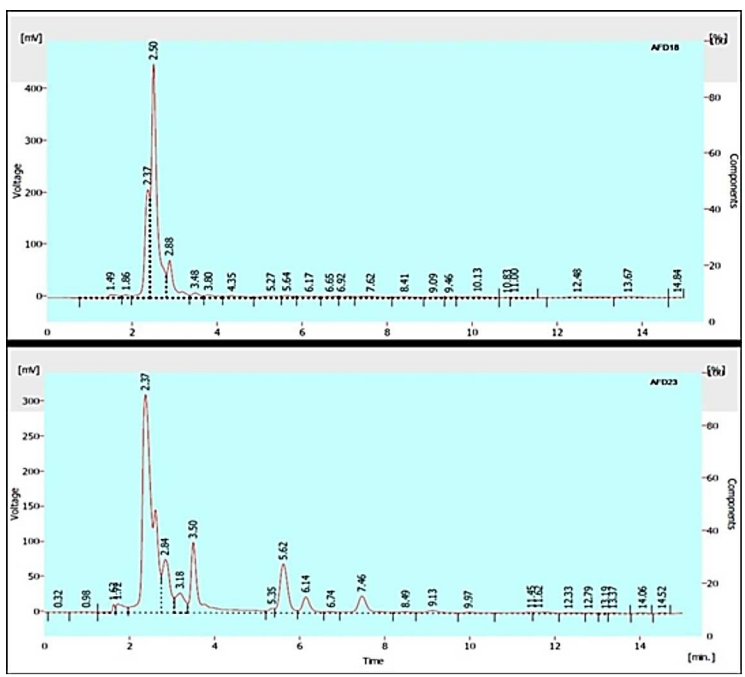

Figure 3: HPLC-UV chromatogram of methanol extract of actinomycete strains AFD18 ( $1^{\text {st }}$ line) and AFD23 $\left(2^{\text {nd }}\right.$ line) with peaks at different retention times $\left(t_{R}\right)$

\section{DISCUSSION}

Antibiotic resistance is emerging at a rate that exceeds the discovery of new drugs. Most antibiotics are produced by actinomycetes which are prolific producers of specialized metabolites or natural products. Due to increase in the advancements of technology, the need to explore the unexplored areas is also increasing. In the present study 30 strains of actinomycetes were isolated from the soil and sand collected from Cholistan desert which is an unexplored ecosystem located in the southern Punjab, Pakistan. These actinomycetes were characterized and identified on the basis of physiological, biochemical and genetic protocols. All of the strains produced hard and embedded colonies on glycerol-casein- $\mathrm{KNO}_{3}$ agar medium which is a characteristic growth pattern of actinomycetes [16].

By biochemical characterization 16 of the strains were capable of producing melanoid pigments which is a characteristic feature of the genus Streptomyces [17]. The strains were able to utilize glucose, fructose and mannose as carbon sources as reported earlier [18]. Streptomyces was considered the most dominant genera isolated from desert soil worldwide in different studies. The identification of any organism up to species level is not only possible through biochemical and physiological testing, but it also requires extensive genetic level identification by comparing 16S rRNA gene sequences with type strains [19]. In the present study, 16S rRNA gene sequencing proved that all of the strains isolated from desert belong to different species of the genus Streptomyces (Table 2) which is in accordance with other reports [20].

An important focus of this study was to identify and maintain a set of test pathogens, i.e methicillin resistant Staphylococcus aureus (MRSA).These strains were confirmed and identified as different strains of MRSA by using the methods described by Abdalrahman and Fakhr [11]. The genetic characterization of $16 \mathrm{~S}$ rRNA gene of these strains also proved that they belong to the genus Staphylococcus aureus and the findings of other researchers also supported this result. Different researchers also characterized MRSA through 16S rRNA gene amplification by PCR [21]. For the identification of MRSA, the genotypic detection of mec-A gene is used as a reference standard worldwide; it is used as an authentic test for the confirmation of MRSA [22]. So, we also used this as a confirmation test for our strains of MRSA along with antibiotics sensitivity against oxacillin, cefoxitin etc.

The main focus of this study was to isolate and identify potent actinomycete strains active against the most resistant pathogens, the MRSA, so for this purpose all of the strains of desert actinomycetes were screened biologically and chemically. A good number of desert actinomycetes exhibited very promising antimicrobial activity (Table 4). The strain AFD2 was very active strain with $36 \mathrm{~mm}$ zone of inhibition, another significant anti-MRSA strain was AFD9 with $30 \mathrm{~mm}$ zone of inhibition, strain AFD10 exhibited $28 \mathrm{~mm}$ zone of inhibition. Altogether $71 \%$ of the total strains of desert actinomycetes exhibited very promising activity against all MRSA strains and this percentage is more than described in various studies [23] conducted for desert actinomycetes. But this percentage is less than that described previously by Tiwari et al [24] who studied the antimicrobial activity of actinomycetes of Thar Desert India. Some actinomycete strains like AFD6, AFD7 did not exhibit any significant antimicrobial activity 
which shows these strains are different in their antimicrobial behavior even then they are obtained from the same source.

In metabolic fingerprinting on TLC plates the crude extracts of these actinomycetes strains showed significant results when treated with anisaldehyde $/ \mathrm{H}_{2} \mathrm{SO}_{4}$ different colored spots including blue, green or violet spots representing the presence of sugar molecules [15]. The treatment with Ehrlich's reagent exhibited blue and yellow colored bands representing the presence of $\mathrm{N}$-heterocyclic compounds as described by Aslam et al [25].

HPLC-UV chromatograms of the crude extracts of these desert actinomycetes provided an insight into the chemical fingerprints of the compounds they contain. Some strains like AFD23 exhibited total 8 peaks at different retention times $\left(t_{R}\right)$ with highest at $2.37 \mathrm{~min}$. Strain AFD18 showed 4 peaks with highest at 2.50 retention time and these results were comparable with the results of Anwar et al [26]. These results showed that all of these strains produce varied antimicrobial compounds that may have the capability to inhibit the growth of resistant pathogens like MRSA. The capacity of the potentially active compounds to resist the pathogenic organisms can be confirmed further by following the extraction and purification methods and by using different column chromatographic techniques. Thin layer chromatography coupled with bioautography is a very useful alternative to detect the antimicrobial compounds in crude extracts. Bioautographic assay of the crude extracts of desert actinomycetes strain specially AFD23 exhibited different fractions of bioactive compounds which showed good antimicrobial activity against MRSA strains. These results are also supported by the findings of Sajid et al [13].

\section{CONCLUSION}

Cholistan desert is an important and rare source of diverse actinomycetes in Pakistan with very potent antimicrobial compounds. The flora of actinomycetes in this unique ecological environment should be explored further by purification and structure elucidation of the active compounds and by affirming their antimicrobial activity for novel drugs against MRSA and other MDRs.

\section{DECLARATIONS}

\section{Acknowledgement}

Financial support for this research work was provided by Higher Education Commission
(HEC) of Pakistan via Indigenous $5000 \mathrm{PhD}$ Fellowship Program under PIN NO. 112-316522BM1-172 to Adeela Fatima is gratefully acknowledged. The Citi Lab Lahore is acknowledged for providing the MRSA strains.

\section{Conflict of Interest}

No conflict of interest associated with this work.

\section{Contribution of Authors}

The authors declare that this work was done by the authors named in this article and all liabilities pertaining to claims relating to the content of this article will be borne by them.

\section{REFERENCES}

1. Huttner A, Harbarth S, Carlet J, Cosgrove S, Goossens $H$, Holmes A, Jarlier, V., Voss, A. Pittet, D. Antimicrobial resistance: a global view from the 2013 World Healthcare-Associated Infections Forum. Antimicrob Resist Infect Control 2013; 2(1): 31.

2. Sievert DM, Ricks $P$, Edwards JR, Schneider A, Patel J, Srinivasan $A$, Kallen $A$, Limbago $B$, Fridkin $S$. Antimicrobial-resistant pathogens associated with healthcare-associated infections summary of data reported to the National Healthcare Safety Network at the Centers for Disease Control and Prevention, 20092010. Infect Control Hosp Epidemiol 2013; 34(01): 1-14.

3. Zafar A, Stone M, Ibrahim S, Parveen Z, Hasan Z, Khan E, Hasan R, Wain J, Bamford K. Prevalent genotypes of meticillin-resistant Staphylococcus aureus: report from Pakistan. J of Infect Dis 2011; 60(1): 56-62.

4. Anthony BM, Helmut L. The Actinomycins. In: Cragg DJ, Kingston GM, Newman DG, editors. Anticancer agents from natural products. 2nd ed. New York: CRC press; 2011.

5. Lam KS. Discovery of novel metabolites from marine actinomycetes. Curr Opin Microbiol 2006; 9(3): 245-251.

6. Baig MS, Akram M, Hassan MA. Possibilities for range development in Cholistan desert as reflected by its physiography and soils. Pak J For 1980; 30(2): 61-65.

7. Arshad M, Ashraf MY, Ahmad M, Zaman F. Morphogenetic variability potential of Cenchrus ciliaris $L$. from Cholistan desert, Pakistan. Pak J Bot 2007; 39(5): 14811488.

8. Hayakawa M, Nonomura H. A new method for the intensive isolation of actinomycetes from soil. Actinomycetol 1989; 3(2): 95-104.

9. Shirling ET, Gottlieb D. Methods for characterization of Streptomyces species1. Int J Syst Evol Microbiol 1966; 16(3): 313-340.

10. Bensultana A, Ouhdouch Y, Hassani L, Mezrioui NE, Rafouk $L$. Isolation and characterization of wastewater sand filter actinomycetes. World J Microbiol Biotechnol 2010; 26(3): 481-487.

Trop J Pharm Res, October 2018; 17(10):2045 
11. Abdalrahman LS, Fakhr MK. Incidence, antimicrobial susceptibility, and toxin genes possession screening of Staphylococcus aureus in retail chicken livers and gizzards. Foods 2015; 4(2): 115-129.

12. Clinical and Laboratory Standards Institute. Performance standards for antimicrobial susceptibility testing; TwentySeventh Informational Supplement, Document M100S2. 2017.

13. Sajid I, Yao CBFF, Shaaban KA, Hasnain S, Laatsch $H$. Antifungal and antibacterial activities of indigenous Streptomyces isolates from saline farmlands: prescreening, ribotyping and metabolic diversity. World J Microbiol Biotechnol 2009; 25(4): 601-610.

14. Lechevalier H. A practical guide to generic identification of actinomycetes. Bergey's manual of systematic bacteriol 1989; 4: 2344-2347.

15. Jork H, Funk W, Fishcer W, Wimmer H. TLC reagents and detection methods-physical and chemical detection methods: activation reactions, reagent sequences, reagents. 2nd ed. NY: Wiley; 1994.

16. Messaoudi O, Bendahou M, Benamar I, Abdelwouhid DE. Identification and preliminary characterization of nonpolyene antibiotics secreted by new strain of actinomycete isolated from sebkha of Kenadsa, Algeria. Asian Pac J Trop Biomed 2015; 5(6): 438-445.

17. Manivasagan $P$, Venkatesan J, Sivakumar K, Kim SK. Actinobacterial melanins: current status and perspective for the future. World J Microbiol Biotechnol 2013; 29(10): 1737-1750.

18. Charousová I, Javoreková S, Medo J, Schade R. Characteristic of selected soil streptomycetes with antimicrobial potential against phytopathogenic microorganisms. J Microbiol Biotech Food Sci 2016; 5(Special): 64-68.
19. Kutzner HJ. The family streptomycetaceae. The prokaryotes- $A$ handbook on habitats, isolation, and identification of bacteria. 1981; 2039: 2075 .

20. Cundell DR, Piechoski MP. Potentially novel Actinobacteria-derived antibiotics from unique microenvironments. Antimicrobials: Synthetic and Natural Compounds: CRC Press; 2015. 83-98 p.

21. Ibed AN, Hamim SS. Molecular detection of methicillin resistant staphylococcus aureus isolated from burns infection in Al-nasiriyah city. W J Pharma Sci 2014; 2: 2321-3086.

22. Stegger A, Andersen P, Kearns A, Pichon B, Holmes $M$, Edwards G, Laurent $F$, Teale $C$, Skov $R$ and Larsen $A R$. et al. Rapid detection, differentiation and typing of methicillin resistant Staphylococcus aureus harbouring either mecA or the new mecA homologue mecALGA251. Clin Microbiol Infect 2012; 18(4): 395400.

23. Nithya $K$, Muthukumar $C$, Duraipandiyan $V$, Dhanasekaran $D$, Thajuddin $N$. Diversity and antimicrobial potential of culturable actinobacteria from desert soils of Saudi Arabia. J Pharm Sci Res 2015; 7(3): 117-122.

24. Tiwari K, Upadhyay DJ, Mösker E, Süssmuth R, Gupta RK. Culturable bioactive actinomycetes from the Great Indian Thar Desert. Ann Microbiol 2015; 65(4): 19011914.

25. Aslam S, Sajid I. Antimicrobial potential of Halophilic actinomycetes against multi drug resistant (MDR) ventilator associated pneumonia causing bacterial pathogens. Pak J Pharm Sci 2016; 29(2): 367-374.

26. Anwar S, Ali B, Qamar F, Sajid I. Insecticidal activity of actinomycetes isolated from salt range, Pakistan against mosquitoes and red flour beetle. Pak J Zool 2014; 46(1): 83-92. 